\title{
Stimulation-induced ectopicity and propagation windows in model damaged axons
}

\author{
Mathieu Lachance ${ }^{1,2^{*}}$, André Longtin ${ }^{2}$, Catherine E Morris ${ }^{3}, \mathrm{Na} \mathrm{Yu}^{2}$, Béla Joós ${ }^{2}$ \\ From The Twenty Third Annual Computational Neuroscience Meeting: CNS*2014 \\ Québec City, Canada. 26-31 July 2014
}

\begin{abstract}
Background
Neural tissue injuries render voltage-gated $\mathrm{Na}^{+}$channels (Nav) leaky, thereby altering excitability, disrupting propagation and causing neuropathic pain related ectopic activity [1]. In both recombinant systems and native excitable membranes, membrane damage causes the kinetically-coupled activation and inactivation processes of Nav channels to undergo hyperpolarizing shifts [2]. This damage-intensity dependent change, now called [3] coupled left-shift (CLS), yields a persistent or "subthreshold" Nav window conductance. Previous simulation work involving various degrees of mild CLS has focused on individual nodes of Ranvier or simple propagation models [3-5], leaving open an important question: does mild-injury (small CLS values, pumps functioning well) render propagation-competent but still quiescent axons vulnerable to further impairments as the system attempts to cope with its normal excitatory inputs? We probed this incipient diffuse axonal injury scenario using a 10-node myelinated axon model with dynamic ion gradients and Nernst potentials.
\end{abstract}

\section{Results}

Fully restabilized axons with mild damage, while they remain quiescent in the absence of stimulation, can abruptly switch behavior after receiving normal impulse traffic from upstream neurons. Because incoming action potentials stress $\mathrm{Na}^{+}$and $\mathrm{K}^{+}$gradients, thereby altering spike thresholds, the damaged nodes of Ranvier can become ectopic signal generators ("ectopic nodes"), emitting neuropathic pain-like (or epileptiform) barrages of impulses. Comparable changes could contribute to diverse acquired sodium channelopathies [6] and to the neuropathic amplification of normally benign sensory inputs [7].

\footnotetext{
* Correspondence: mathieu.lachance@cegepoutaouais.qc.ca 'Département de physique, Cégep de I'Outaouais - campus Félix-Leclerc, Gatineau, Québec, Canada J8T 7T7

Full list of author information is available at the end of the article
}

Also, and perhaps counter-intuitively, more intensely damaged sites firing ectopically can be dominated by incoming high-frequency impulse traffic, enabling a "propagation window" of finite lifetime. This intermittent "propagation window" is a robust phenomenon, occurring despite noise, large jitter and the presence of several consecutive ectopic nodes. Complex input spike patterns then propagate with good fidelity as long as their frequencies exceed the ectopic frequency. The faithful propagation of such impulse trains through a damaged zone is likely to complicate diagnosis.

\section{Authors' details}

'Département de physique, Cégep de l'Outaouais - campus Félix-Leclerc, Gatineau, Québec, Canada J8T 7T7. ²Ottawa-Carleton Physics Institute, University of Ottawa, Ottawa, Ontario, Canada K1N 6N5. ${ }^{3}$ Neurosciences, Ottawa Hospital Research Institute, Ottawa, Ontario, Canada K1H 8M5.

Published: 21 July 2014

\section{References}

1. Wolf JA, Stys PK, Lusardi T, Meaney D, Smith DH: Traumatic axonal injury induces calcium influx modulated by tetrodotoxin-sensitive sodium channels. J Neurosci 2001, 21(6):1923-1930.

2. Wang JA, Lin W, Morris T, Banderali U, Juranka PF, Morris CE: Membrane trauma and Na+ leak from Nav1.6 channels. Am J Physiol Cell Physiol 2009, 297(4):C823-C834.

3. Boucher PA, Joós B, Morris CE: Coupled left-shift of Nav channels: modeling the $\mathrm{Na}+$-loading and dysfunctional excitability of damaged axons. J Comput Neurosci 2012, 33(2):301-319.

4. Yu N, Morris CE, Joós B, Longtin A: Spontaneous excitation patterns computed for axons with injury-like impairments of sodium channels and $\mathrm{Na} / \mathrm{K}$ pumps. PLoS Comput Biol 2012, 8(9):e1002664

5. Volman $\mathrm{V}, \mathrm{Ng} \mathrm{LJ}$ : Computer Modeling of Mild Axonal Injury: Implications for Axonal Signal Transmission. Neural Comput 2013, 25(10):2646-2681.

6. Morris CE, Boucher PA, Joós B: Left-shifted Nav channels in injured bilayer: primary targets for neuroprotective Nav antagonists? Frontiers Pharmacol 2012, 3:19.

7. Costigan M, Scholz J, Woolf CJ: Neuropathic pain: a maladaptive response of the nervous system to damage. Annu Rev Neurosci 2009, 32:1.

\section{doi:10.1186/1471-2202-15-S1-P134}

Cite this article as: Lachance et al: Stimulation-induced ectopicity and propagation windows in model damaged axons. BMC Neuroscience 2014 15(Suppl 1):P134. 